by Mike Katz

\title{
Social responsibility in geoscience education workshops
}

Mineral Consultant, Sydney Australia; *Corresponding author, E-mail: mikekatz320@gmail.com

(Received: February 20, 2020; Revised accepted: April 23, 2020)

https://doi.org/10.18814/epiiugs/2020/020062

This paper considers the need to introduce social responsibility course content into the undergraduate university geosciences study curriculum as a result of outcomes of workshops and presentations. The aim of this new initiative is to make the students aware that their studies are not only a technical pathway to professional qualifications but also a requisite in their education to strengthen their social skills. As most of these students will be employed by the extractive industries including the environment sector they should be mindful that there are now major social impact issues developing worldwide. These include the requirement of a social license to operate, together with corporate social responsibility standards and in the case of Indigenous People the need for free, prior and informed consent. The workshops, which were attended by staff, students and other stakeholders interested in this topic all agreed in principle that it is important and should be further developed. However in the present situation, it is often relegated to a minor subject and more likely, it is not introduced at all. It is apparent that this social responsibility topic is an important component of the recent development of the geoethics initiative.

\section{Introduction}

My interests in social responsibility in geoscience education were developed during an academic career at the School of Applied Geology and the Key Centre for Mines, University of New South Wales, Sydney Australia from 1971-2009 and as a Councilor for the Association of Geoscientists for International Development (AGID) from 1976-1984. Most undergraduate geoscience courses and fieldwork projects are technical with little regard to social implications and engagement with local communities. As new technology progresses the educational content increases and the syllabus is often full to capacity. However the introduction of socially responsible courses should be considered as an important content in the syllabus. Social awareness input would make the students more balanced in their skills, especially in developing countries, which are often dependent on and socially negatively impacted by the development of their mining and oil/gas resources.

Workshops to discuss social responsibility as a requirement in undergraduate courses were first proposed at the 2012 International Geological Congress (IGC) held in Brisbane, Australia and at the Social Responsibility in Mining (SRM) Congress in Santiago, Chile in 2013 with much interest to further develop this topic. The first workshop was invited and held during the GEMDEC 2014 Seminar at Utkal University, Bhubaneswar, India. The aim of the workshops was to discuss and debate the needs, ways and means of introducing appropriate socially responsible content into the undergraduate university geoscience education study programs. This knowledge should be practiced in their fieldwork where there is opportunity for community engagement. Ideally as the student progresses to their final year, the field project report would include a community engagement component.

\section{Methods and Materials}

\section{Social Responsibility in Geosciences Study Programs}

Most geoscience students will be employed by industry, a minor number in government, and in the environmental and NGO sectors. Students should be aware that social issues related to sustainable mineral development are becoming more and more important. and the following issues are discussed in Vanclay and Hanna (2019).

- Social license - Communities accept a project to operate with legal, social and economic legitimacy

- Corporate social responsibility (CSR) - Companies adopt policies and practices to reflect their commitment to local communities

- Free, prior and informed consent (FPIC) - Must be obtained from Indigenous People before mining

These pressing socially related issues are currently lacking in the undergraduate geosciences study curriculum and a literature review shows virtually no examples. However in many universities and colleges in North America, Australia and Europe, it may be introduced in an environmental course. For example, an email (J. Gierke, chairman of the Department of Geological and Mining Engineering and Sciences, Michigan Tech personal communication, 3 February 2016) states "In terms of social responsibility there is one undergraduate course where social responsibility is pervasive: Environmental Geology" (see also Gosselin et al., 2016). Geoethics (Peppoloni and Di Capua, 2015), the concept that explores the overlap between geosciences and ethics, has important social responsibility implications, and this subject has been proposed to be introduced into the undergraduate programs in Canada and elsewhere (Ryan and Bank, 2017). Three universities in 
the USA have commenced CSR course modules for their mining and petroleum-engineering students that may be relevant to other areas of geoscience education as well (Smith and Lucena, 2018). In Latin America, Asia and Africa these educational programs are lacking where they are most needed (Maier et al., 2014).

\section{Workshops and Presentations}

The workshops and presentations were made at international conferences in both developed and less - developed countries that have important responsible mining sectors (Table 1). They were widely publicized to survey the interests from a variety of academics, as well as from industry, government and NGO stakeholders. The workshops were conducted as a conference half - day activity with the request to the organizers for as much student participation as possible. After a brief introduction the participants were sorted into appropriate groups, each group having a rapporteur. The participants were encouraged to discuss the workshop topics in an open and free discourse and each rapporteur presented a summary of the discussions. The workshop convener reviewed and collated the summaries and made a draft report which was later circulated for further comments. Oral presentations on social responsibility in geoscience education were given when there were no opportunities for workshops. The lectures were part of a larger conference session and were followed by a brief question and answer period. Further discussions were held with the participants during lunch and post meeting follow-ups.

\section{Results and Discussion}

\section{Workshops}

These were presented in 2014, 2016 and 2018 and were successful especially where academics and significant numbers of students were involved in the group discussions and presentations (Table 1).

The 2014 workshop 'Geoscience Students Development for Society' was held at the Utkal University Department of Geology, 'Geosciences for Mineral Development and Environmental Changes Seminar' in Bhubaneswar, India on January $19^{\text {th }}$ and was supported by the International Union of Geological Sciences (IUGS) Committee on Geological Education. The seminar was located in the mineral rich State of Orissa, which has poor and Indigenous communities that are socially impacted by mineral development. The workshop attracted about 60 students and staff from the Department of Geology and government and industry seminar attendees and was assisted by B.M. Faruque, former Director of the Geological Survey of India. The participants were organized in local student and staff discussion groups. There was also a group from government and another from industry. The topics presented included:

- Social responsibility course and fieldwork content

- Staff skills that would be required to present these courses

- Communication gaps between students and staff

- Government and industry support

- Input from the community on the need for this type of course

The main topic of discussion was the apparent communication gaps that exist between the staff and the students on the awareness of these issues. The staff should take the lead but lack experience, skills, resources, time and motivation. All of this could be done informally by community interaction well before the commencement of any field project. The village chief and the local government officials are the essential points of contact to develop good relations with the local community. The local languages, cultures and traditions have to be taken into account and would be best served by inviting a community member to assist. Other issues that were discussed include the influence of active anti-mining NGOs that have media attention. This is a critical problem that should be addressed by making them more aware of the positive and negative aspects of mineral development by internal or outside lectures by experts. A campaign of public awareness where students, staff and the communities are seen to be working together and sharing knowledge should be beneficial to all concerned. The outcome of the workshop was that the formal introduction of socially responsible courses into the academic program would be beneficial, but would need further development. At this time the main issue was initiating public awareness. The support, cooperation and collaboration of government and industry are essential for sustainable results.

'Social Responsibility in Geoscience Education Workshop' was convened at the 2016 International Geological Congress (IGC) in Cape Town, South Africa on August $28^{\text {th }}$. Limited attendance at the workshop was due to lack of interest in this topic and more concern by the congress participants for the more popular technical workshops and short courses offered at the same period. An absence of student participants was due to the extra workshop registration fees. The attending group of about 20 roundtable participants from mainly African government, industry and academia were very active and informative and a list of the discussion points and outcomes were summarized as follows.

- Is there a need for this to be introduced?

Students should be aware of their social responsibility

- Is there space for these courses in the curriculum?

Not as a formal subject but lectures and research would be beneficial

- Are relevant courses and resources available at present?

Environmental courses could have the necessary content

- Are there fieldwork opportunities for the student to contact the community?

It's not always possible, as fieldwork is not always offered

- Does the staffs have the experience and interest in running these courses?

The course is not considered as a core subject

- Does the geoscience department support the introduction of these courses?

These courses should be promoted and encouraged

- Does Government and industry support the introduction of these courses?

Industry stewardship should take the lead over Government

-What is the best way to involve the community?

Engaging the community to encourage their trust and cooperation

Topics raised included the need for students visits to small-scale mines and that graduates when employed will eventually learn about social responsibility on the job

'Social Responsibility in Earth Science Education Workshop' was held at First International Congress on Geosciences titled "Earth Sciences for Society" at the Faculty of Sciences, University Chouaiib Douk- 
kali, El Jadida, Morocco, 20th March 2018. Sixty participants attended, mainly local students, some academics and other congress attendees. They organized themselves into several working groups to again review the discussion points that were raised in the previous workshop (see above). After group deliberations several rapporteurs made their statements and the outcomes are summarized as follows.

- There was a consensus for university students to have social responsibility skills and that it should also be introduced at more basic school/college levels. Society and geoscience development links are important for everyday life

- Although there is little provision for these courses, ideally the curriculum should have a course in social responsibility for accreditation

- Collaboration with social science departments and faculties would enhance the available resources to aid in the development of the course

- Fieldwork should also be organized to inform the community of the social and environmental risks and the benefits of mining

- There is virtually no staff interest and experience now, but this could be developed in the future by including a social topic in their research

- There is a general lack of university, faculty and department support for these courses, but this could be developed in the future by making the universities aware that the earth sciences can help to avoid social problems.

- Collaboration with government and especially industry is important, in order to get practical advice and resources. Government decision makers should be aware that, socially responsible geoscientists are very much needed when there are mining and natural disasters

- Community involvement would be best served by, presenting lectures and seminars in towns and villages and listening to their views and opinions

- Social and print media can also be used to raise awareness

\section{Presentations}

Presentations in 2012,2013, 2018 and 2019 (Table 1) were made at international conferences where technical sessions predominated. Social impact of mining and mineral development aspects such as community engagement, tailings containment and mine closure were commonly addressed, however topics related to university undergraduate social responsibility education issues were usually absent. The limited feedback on these presentations were mainly from academic delegates from Western countries who claimed that these issues were somewhat covered in their environmental courses and in on the job experience after graduation. It was also acknowledged that the departmental technical core course programs were too overloaded to make enough space, staff and resources to include social content. Comments from academic delegates in less developed countries were more positive, with the main reaction being, how to include these social issues in an already tight teaching program with limited capability. There was some positive consideration given to the idea of including community engagement meetings during the field exercises and the addition of a social component in the final year student reports and theses.

\section{Recommendations}

The outcomes of these workshops and presentations are qualitative at best but do reveal that introducing social responsibility into the geoscience curricula is highly relevant. This should be followed up by more quantitative research directed to undergraduate geoscience departments and students and other stakeholders. In the first instance a departmental and student questionnaire should be designed to assess and evaluate this subject with the following suggested simple headings:

For the department:

- Is there a social responsibility component presented in the syllabus?

- If so please describe the content

- Do you have the necessary staff skills and resources to support this content?

- In the field exercises is there any social outreach or community engagement?

- In the senior year report are there compulsory/ voluntary social components?

- Is there a need to introduce this in your class / field program?

\section{Table 1. Workshops and presentations}

Geosciences for Mineral Development and Envi- IUGS Workshop

ronmental Challenges GEMDEC 2014 -Depart- Geoscience Students Development for Society

ment of Geology, Utkal University,

Bhubaneswar, India

International Geological Congress (IGC) 2016, IGC Workshop 3

Cape Town South Africa

Earth Science for Society 2018, Chouaib Doukali Workshop 1

University, El Jadida, Morocco

IGC 2020, New Delhi, India

IGC 2012, Brisbane, Australia

Chile

Resources for Future Generations RFG 2018,

Vancouver, Canada

Sustainable Development in the Mining Industry Social Responsibility in Mining SDIMI 2019, Sydney, Australia
Students, academics, industry and government working groups

Government, industry, NGOs, academics

Academics and many students

Postponed due to COVID 2019

Workshop WSC07 Social Responsibility in Geoscience Education

AGID Session
Students as principal stakeholders for geoscientific

awareness for sustainable development

Plenary

Education for Social Responsibility in Mining

Expanding the Traditional Classroom

Social Responsibility in Geoscience Education

Social Responsibility in Geoscience and Mining Education
Academics with some students

Government, industry, NGOs, academics with some students

Small mixed audience

Mixed audience 
For the student:

- Are you aware of social responsibility issues in your studies?

- Is this compatible with your technical subjects?

- Would you be interested to have this subject in your course and fieldwork?

- In your field studies is it important to engage outside people?

- Do you understand the meaning of stakeholder participation?

\section{Conclusions}

This paper stresses the need to develop and to introduce social responsibility content into the undergraduate geoscience syllabus. These social issues are an important requirement in the mining and oil/gas industries including the environmental sector where most of these students will be employed. However a literature search indicates that there is an absence of socially responsible content in the geoscience education syllabus. The workshops discussions and outcomes demonstrate the need to introduce this subject. The main barrier is to find the space in the syllabus for social content. If this content was introduced it would make the graduates more capable of engaging communities, especially in the developing countries that are dependent on their minerals. Geoscientists with these additional, important social and geoethical professional qualifications will be best able to serve their communities and country well into the future for sustainable outcomes. This is in accordance with the importance of social governance issues in the geosciences and the global goals for sustainable development (Stewart and Gill, 2017)

\section{Acknowledgements}

The first workshop in 2014 was supported by a grant from the Australian India Council.

\section{References}

Gosselin, D., Burian, S., Lutz, T., and Maxson, J., 2016, Integrating geoscience into undergraduate education about environment, society and sustainability using place-based learning. Journal of Environmental Studies and Sciences, v. 6, pp. 531-541.

Maier, R.M., Diaz-Barriga, F., Field, J.A., Hopkins, J., Klein, B., and Poulton, M.M., 2014, Socially responsible mining: the relationship between mining and poverty, human health and the environment. Reviews on Environmental Health, v. 29, pp. 83-89.

Peppoloni, S., and Di Capua, G., 2015, Geoethics: the Role and Responsibility of Geoscientists. Geological Society of London, Special Publication 419.

Ryan, A.M., and Bank, C.G., 2017, The need for geoethics awareness from a Canadian perspective. Geosciences, v. 7, pp. 120.

Smith, J.M., and Lucena, J.C., 2018, Social responsibility in engineering education and practice: alignments, mismatches, and future directions. 2018 ASEE Annual Conference and Exposition, Salt Lake City, Utah. https://peer.asee.org/30973.

Stewart, I.S., and Gill, J.C., 2017, Social geology - integrating sustainability concepts into Earth Sciences. Proceedings Geologists Association, v. 128 , pp. $165-172$.

Vanclay, F., and Hanna, P., 2019, Conceptualizing company response to community protest: Principles to achieve a social license to operate. Land, v. 8, pp. 101

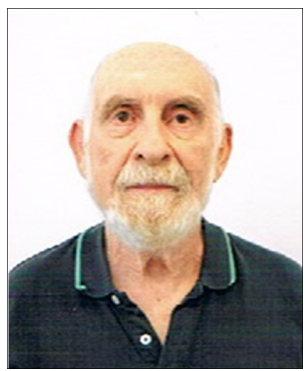

Mike Katz ( $\mathrm{PhD}$ University of Toronto) former Senior Lecturer in Applied Geology, from 1971 - 1988, Director Key Centre for Mines - KCM 1995 - 1998 and Manager, KCM International 1988 - 2009, University of New South Wales, Sydney Australia has 60 years extensive experience in geological and mining education, training and as an expert for academia, government and industry. Now a consultant in international mineral development he has worked with AUSAID, UNDP, ADB and other funding agencies on over 70 projects in 25 countries, mainly in Asia, starting up with an assignment for Canadian International Development Agency for the development of the first Department of Geology, University of Ceylon - Sri Lanka from 1967 - 1970. From 1960 - 1967 worked in Canada in mineral exploration and as geologist for the Quebec Government. 